\title{
Inhomogeneous effect of particle size on core-level and valence- band electrons: Size-dependent electronic structure of Cu3N nanoparticles
}

\section{$\operatorname{AUTHOR}(\mathrm{S})$ :}

Balamurugan, B; Maruyama, T

\section{CITATION:}

Balamurugan, B ...[et al]. Inhomogeneous effect of particle size on core-level and valenceband electrons: Size-dependent electronic structure of CU3N nanoparticles. APPLIED PHYSICS LETTERS 2006, 89(3): 033112.

\section{ISSUE DATE:}

2006-07-17

URL:

http://hdl.handle.net/2433/39683

\section{RIGHT:}

Copyright 2006 American Institute of Physics. This article may be downloaded for personal use only. Any other use requires prior permission of the author and the American Institute of Physics. 


\title{
Inhomogeneous effect of particle size on core-level and valence-band electrons: Size-dependent electronic structure of $\mathrm{Cu}_{3} \mathrm{~N}$ nanoparticles
}

\author{
B. Balamurugan ${ }^{\mathrm{a})}$ and Toshiro Maruyama \\ Department of Chemical Engineering, Graduate School of Engineering, Kyoto University, \\ Kyoto 615-8510, Japan
}

(Received 20 March 2006; accepted 14 June 2006; published online 19 July 2006)

\begin{abstract}
The present study reports a clear evidence and physical significance of an inhomogeneous effect of particle size on electrons originating from various electronic levels of copper nitride nanoparticles. $\mathrm{X}$-ray photoelectron and optical absorption spectroscopy studies reveal that a direct modification of the valence band due to size effects explained by the more appropriate surface bond contraction model results in a strong increase in the binding energy of valence-band electrons as compared to core-level electrons. () 2006 American Institute of Physics. [DOI: 10.1063/1.2227632]
\end{abstract}

Size-induced modifications in the electronic structure of semiconductor nanoparticles are expected to result in fascinating optical and electronic properties. ${ }^{1,2}$ The consequences of these size effects have been widely observed in the macroscopic properties such as optical band gap, conductivity type, carrier concentrations, electrical resistivity, and device characteristics. $^{3-7}$ To understand the origin of the sizedependent properties, it is important to study the direct influence of particle size on electrons, which is addressed by a few theoretical observations describing the modified density of states, discrete band structure, and changes in the edges of valence and conduction bands. ${ }^{8,9}$ However, limited experimental studies using x-ray photoelectron spectroscopy (XPS) present the size-induced changes in the electronic structure of nanoparticles but mostly describe the binding energy and shape of the spectral features of core electrons. ${ }^{10-13}$ Size effects are expected to have strong impact on the properties originating from valence-band as revealed by a strong shift in the valence band edge away from the Fermi level and associated conductivity-type inversion in nanoparticles. ${ }^{4,14}$ Thus, a systematic study on the effect of particle size on valence-band and core-level electrons is highly desirable for the fundamental understanding of the nanoparticle characteristics.

The present study provides a direct experimental evidence on how the particle size influences the electrons originating from various electronic levels by studying the sizedependent electronic structure of copper nitride $\left(\mathrm{Cu}_{3} \mathrm{~N}\right)$ nanoparticles using XPS and optical absorption (OA) spectroscopy. $\mathrm{Cu}_{3} \mathrm{~N}$ is a promising semiconductor having suitable optical and electronic properties for potential device applications. ${ }^{15-17}$ For sample preparations, $\mathrm{Cu}_{3} \mathrm{~N}$ nanoparticles have been deposited on carbon coated molybdenum grids, quartz, and silicon substrates by reactively sputtering a highly pure copper target in high purity argon (Ar) and nitrogen $\left(\mathrm{N}_{2}\right)$ plasma ambient using a radio frequency (rf) (frequency of $13.5 \mathrm{MHz}$ ) magnetron sputtering. Particle size has been varied by varying the deposition time $\left(t_{\text {dep }}\right)$ as 10,15 , 20, 30, and $240 \mathrm{~s}$, while keeping the deposition pressure (5 mTorr), substrate temperature (room temperature), rf power $(60 \mathrm{~W})$ and flow rates of Ar [3 SCCM (SCCM de-

\footnotetext{
a) Author to whom correspondence should be addressed; electronic mail:
} bala@cheme.kyoto-u.ac.jp notes cubic centimeter per minute at STP)] and $\mathrm{N}_{2}$ (30 SCCM) as constants. Particle size, distribution, and structure of $\mathrm{Cu}_{3} \mathrm{~N}$ nanoparticles have been studied using transmission electron microscope (TEM), atomic force microscope (AFM), glancing angle x-ray diffraction (GAXRD), and XPS (in which $\operatorname{Mg} K \alpha$ excitation was used) measurements. These studies show that isolated $\mathrm{Cu}_{3} \mathrm{~N}$ nanoparticles have been formed at $t_{\mathrm{dep}} \leqslant 20 \mathrm{~s}$, and $t_{\mathrm{dep}} \geqslant 30 \mathrm{~s}$ has resulted in the formation of nanoparticle films due to an extended nucleation and growth of the sputtered atoms at larger $t_{\text {dep }}$ as shown in a typical TEM micrograph [Fig. 1(a)] and AFM image [Fig. 1(b)] of $\mathrm{Cu}_{3} \mathrm{~N}$ nanoparticles deposited for 10 and $240 \mathrm{~s}$, respectively. Thus, average particle size in nanoparticle samples prepared for $10 \mathrm{~s}(4.8 \mathrm{~nm}), 15 \mathrm{~s}(8.5 \mathrm{~nm})$, and $20 \mathrm{~s}(10.0 \mathrm{~nm})$ has been estimated from TEM micrographs and that for the samples prepared for $30 \mathrm{~s}(15.7 \mathrm{~nm})$ and $240 \mathrm{~s}(21.4 \mathrm{~nm})$ has been estimated from AFM images. In addition, $\mathrm{Cu}_{3} \mathrm{~N}$ nanoparticles crystallize into a cubic anti$\mathrm{ReO}_{3}$ structure with a predominant (100) peak along with weak intensity (200) and (210) peaks as shown in the x-ray diffractogram of $\mathrm{Cu}_{3} \mathrm{~N}$ nanoparticles deposited for $240 \mathrm{~s}$ [Fig. 1(c)].
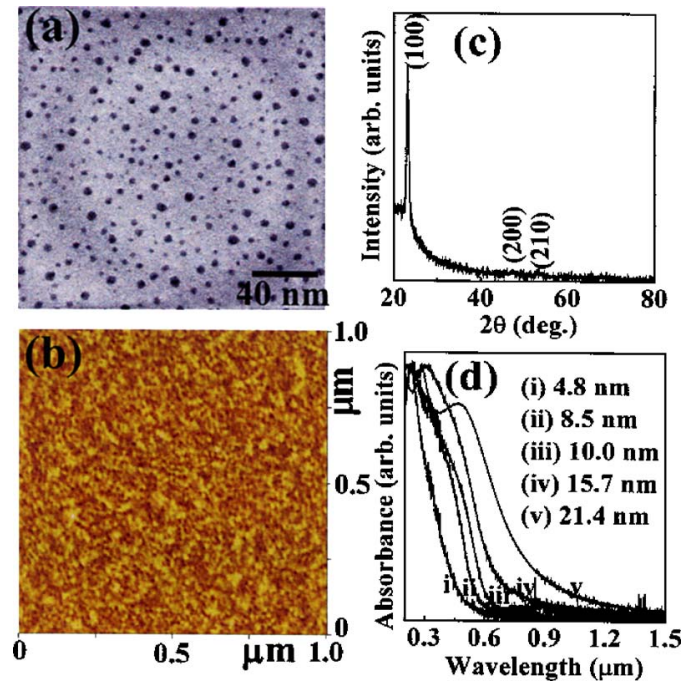

FIG. 1. (Color online) TEM micrograph and $\mathrm{AFM}$ image of $\mathrm{Cu}_{3} \mathrm{~N}$ nanoparticles deposited for $10 \mathrm{~s}$ (a) and $240 \mathrm{~s}$ (b), respectively. X-ray diffractogram of $\mathrm{Cu}_{3} \mathrm{~N}$ nanoparticles deposited for $240 \mathrm{~s}$ (c) and OA spectra of $\mathrm{Cu}_{3} \mathrm{~N}$ nanoparticles having different average particle sizes (d) are also shown. 


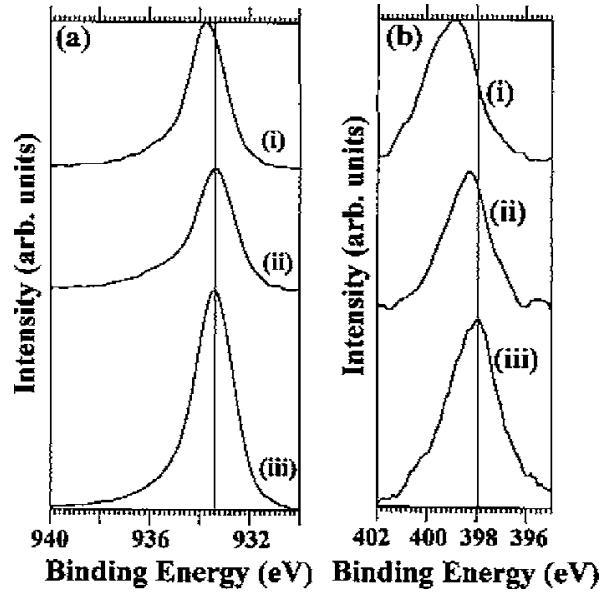

FIG. 2. XPS spectra of $\mathrm{Cu} 2 p_{3 / 2}$ (a) and $\mathrm{N} 1 s$ electrons (b) of $\mathrm{Cu}_{3} \mathrm{~N}$ nanoparticles having different average particle sizes: (i) $4.8 \mathrm{~nm}$, (ii) $8.5 \mathrm{~nm}$, and (iii) $10.0 \mathrm{~nm}$

The electronic structure of $\mathrm{Cu}_{3} \mathrm{~N}$ nanoparticles has been studied using XPS and OA techniques. XPS spectra of $\mathrm{Cu}$ $2 p_{3 / 2}$ [Fig. 2(a)] and $\mathrm{N} 1 s$ electrons [Fig. 2(b)] of $\mathrm{Cu}_{3} \mathrm{~N}$ nanoparticles clearly reveal a shift in their peak positions towards the higher binding energy side on decreasing the particle size to $4.8 \mathrm{~nm}$. In the electronic structure of $\mathrm{Cu}_{3} \mathrm{~N}$, $\mathrm{Cu} 1 s, \mathrm{Cu} 2 s, \mathrm{Cu} 2 p, \mathrm{Cu} 3 s, \mathrm{Cu} 3 p$, and $\mathrm{N} 1 s$ states belong to core electronic levels and, on the other hand, $\mathrm{Cu} 3 d, \mathrm{Cu}$ $4 s, \mathrm{Cu} 4 p$ and $\mathrm{Cu} 4 d$ levels participate in the formation of valence band along with the $\mathrm{N} 2 s, \mathrm{~N} 2 p, \mathrm{~N} 3 s, \mathrm{~N} 3 p$, and $\mathrm{N}$ $3 d$ electronic levels. ${ }^{17}$ In addition to the XPS spectra of core electrons $\left(\mathrm{Cu} 2 p_{3 / 2}\right.$ and $\left.\mathrm{N} 1 s\right)$, the changes in the valence band can also be obtained during XPS measurements by recording the spectral features corresponding to $\mathrm{Cu} L_{3} V V$ and $\mathrm{Cu} L_{3} M_{23} V$ Auger transitions. ${ }^{18}$ During $L_{3} V V$ transition, a valence-band electron fills a previously created core $\left(L_{3}\right)$ hole and its excess energy causes ionization of a second valence-band electron, and in case of $L_{3} M_{23} V$ transition, a core electron $\left(M_{23}\right)$ fills a previously created core $\left(L_{3}\right)$ hole and its excess energy causes ionization of another valenceband electron. ${ }^{18,19}$ The recorded spectral features corresponding to $\mathrm{Cu} L_{3} V V$ [Fig. 3(a)] and $\mathrm{Cu} L_{3} M_{23} V$ [Fig. 3(b)] Auger transitions are also observed to be size dependent and exhibit a strong shift as compared to XPS spectra of $\mathrm{Cu} 2 p_{3 / 2}$ and $\mathrm{N}$
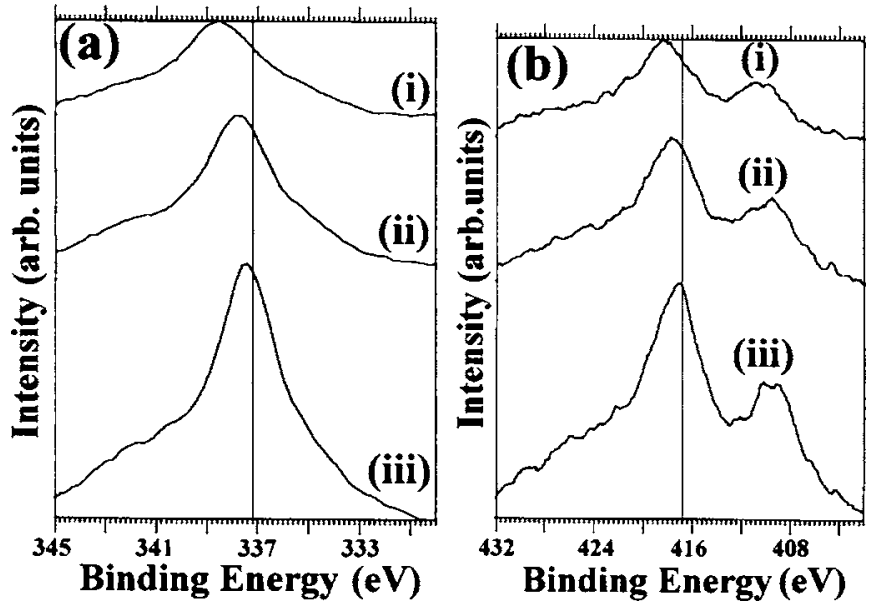

FIG. 3. The recorded $\mathrm{Cu} L_{3} V V$ (a) and $\mathrm{Cu} L_{3} M_{23} V$ (b) Auger transitions of $\mathrm{Cu}_{3} \mathrm{~N}$ nanoparticles having different average particle sizes: (i) $4.8 \mathrm{~nm}$, (ii)

transition between the band edges, and the size-induced blue-
Downloaded 31 May 2007 to 130.54.110.22. Redistribution subject to AIP license or copyright, see http://apl.aip.org/apl/copyright.jsp

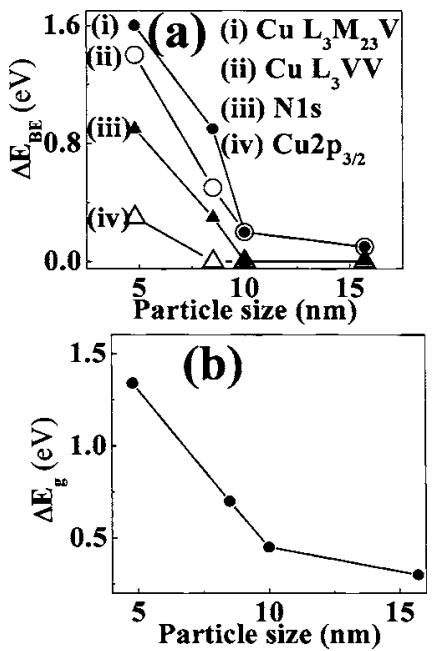

FIG. 4. A plot of $\Delta E_{\mathrm{BE}}$ vs particle size for various spectral features recorded during XPS measurements of $\mathrm{Cu}_{3} \mathrm{~N}$ nanoparticles (a). Size-induced shift in the band gap $\left(\Delta E_{g}\right)$ is also plotted as a function of particle size (b).

$1 s$ electrons. With no considerable shift observed in the peak positions of both the XPS and Auger transitions of nanoparticles prepared for $t_{\text {dep }} \geqslant 30 \mathrm{~s}$ (particle size $\geqslant 15.7 \mathrm{~nm}$ ), the peak positions of those transitions corresponding to $\mathrm{Cu}_{3} \mathrm{~N}$ nanoparticles deposited for $240 \mathrm{~s}$ (particle size $=21.4 \mathrm{~nm}$ ) have been taken as corresponding bulk values (marked as a line in Figs. 2 and 3). The shift in the peak positions with respect to the bulk value $\left(\Delta E_{\mathrm{BE}}\right)$ for $\mathrm{Cu} 2 p_{3 / 2} \mathrm{~N} 1 s, \mathrm{Cu} L_{3} V V$, and $\mathrm{Cu} L_{3} M_{23} V$ transitions is plotted as a function of particle size [Fig. 4(a)]. On decreasing the particle size to $4.8 \mathrm{~nm}$, the peak position of the XPS spectra of $\mathrm{Cu} 2 p_{3 / 2}$ and $\mathrm{N} 1 s$ core electrons exhibit an increase of 0.3 and $0.9 \mathrm{eV}$, respectively, with respect to the bulk value, where as that of $\mathrm{Cu}_{L_{3}} V V$ and $\mathrm{Cu} L_{3} M_{23} V$ Auger transitions originating from the valence band exhibit a strong increase of 1.4 and $1.6 \mathrm{eV}$ in their peak positions, respectively. These results clearly reveal that the effect of size in the binding energy of electrons is not homogeneous across the band structure of $\mathrm{Cu}_{3} \mathrm{~N}$ nanoparticles. In brief, the present study shows that the binding energy of the spectral features ( $\mathrm{Cu} L_{3} V V$ and $\mathrm{Cu} L_{3} M_{23} V$ transitions) originating from the valence band is strongly influenced by the nanoparticle nature of $\mathrm{Cu}_{3} \mathrm{~N}$ than that of the spectral features (XPS spectra of $\mathrm{Cu} 2 p_{3 / 2}$ and $\mathrm{N} 1 s$ electrons) corresponding to the core electronic levels.

As observed by XPS studies, the modified electronic structure of $\mathrm{Cu}_{3} \mathrm{~N}$ nanoparticles is also evident from the sizeinduced blueshift of their OA spectra [Fig. 1(d)]. To estimate the band gap, Tauc's plots $\left[(\alpha h \nu)^{1 / n}\right.$ vs $h \nu$ curves] were plotted for different $n$ values $(n=1 / 2,3 / 2,2,3)$ and the best linear relationship was obtained by plotting $(\alpha h \nu)^{2}$ against photon energy $(h \nu)(n=1 / 2)$, indicating a direct band gap nature of $\mathrm{Cu}_{3} \mathrm{~N}$ nanoparticles. ${ }^{20}$ The transition of electrons from the valence-band minimum to conduction band maximum (which lie above each other in momentum space) in direct band gap materials will directly take place upon absorption of photons without a phonon mediation, known as electronphonon coupling, which is expected during the OA process for conserving the momentum in indirect band gap semiconductors (in which the momenta of the valence-band maximum and conduction-band minimum are not the same). ${ }^{21}$ Thus, the $\mathrm{OA}$ of $\mathrm{Cu}_{3} \mathrm{~N}$ nanoparticles arises only from the transition between the band edges, and the size-induced blueAIP license or copyright, see http://apl.aip.org/apl/copyright.jsp 
shift in the band gap $\left(\Delta E_{g}\right)$ with respect to bulk value (corresponding to $21.4 \mathrm{~nm}$ particle size) has been plotted [Fig. 4(b)].

An evidence of an inhomogeneous effect of particle size in the binding energy of core-level and valence-band electrons along with a size-induced band gap expansion is an important result of the present study. As compared to bulk materials, the size effects are expected to influence the electronic structure of nanoparticles, which results in sizedependent optical and electronic properties. For better understanding of the present results, it is more suitable to point out the surface bond contraction model, which explains both the band gap expansion and increase in the binding energy of core-level electrons of nanoparticles. According to this model, the modified crystal field at nanodimensions, which is determined by the contraction of surface bonds in conjunction with an increase in the surface to volume ratio of nanoparticles, has been observed to result in an expansion of band gap $^{22}$ and an increase in the binding energy of core electrons. ${ }^{11,23-25}$ Thus, the size-induced increase of the peak position of core-level XPS spectra and band gap expansion in $\mathrm{Cu}_{3} \mathrm{~N}$ nanoparticles are in good agreement with the surface bond contraction model. In addition, size-dependent increase in the band gap of $\mathrm{Cu}_{3} \mathrm{~N}$ nanoparticles with respect to bulk value [Fig. 4(b)] together with the surface bond contraction model also reveals a direct and strong modification of valence and conduction bands. ${ }^{26-29}$ In particular, the expansion of band gap is the combination of the size-induced shifts in the edges of the valence $\left(\Delta E_{v}\right)$ and conduction bands $\left(\Delta E_{c}\right)$ in which $\Delta E_{v}$ is expected to be stronger than $\Delta E_{c}{ }^{4,9,29}$ Thus, a direct modification of the valence band due to the size effects results in a strong increase in the binding energy of valence-band electrons as compared to core-level electrons and leads to inhomogeneous changes in the electronic structure of $\mathrm{Cu}_{3} \mathrm{~N}$ nanoparticles with respect to particle size.

In conclusion, the present study reveals an experimental evidence of an inhomogeneous effect of particle size on electrons originating from the valence band and deep core levels of $\mathrm{Cu}_{3} \mathrm{~N}$ nanoparticles. XPS and $\mathrm{OA}$ studies reveal that a size-induced shift in $\Delta E_{v}$ with a decrease in particle size to $4.8 \mathrm{~nm}$ leads to a strong increase in the binding energy of valence-band electrons as compared to that of core-level electrons. The observed size-induced changes in the electronic structure are important to understand the optical and electronic properties of nanoparticles.
One of the authors (B.B.) acknowledges the financial support from Japan Society for the Promotion of Science (JSPS).

${ }^{1}$ M. Shim, C. Wang, and P. G. Sionnest, J. Phys. Chem. 105, 2369 (2001). ${ }^{2}$ N. Y. Morgan, C. A. Leatherdale, M. Drndić, M. V. Jarosz, M. A. Kastner, and M. Bawendi, Phys. Rev. B 66, 075339 (2002).

${ }^{3}$ K. Sattler, in Handbook of Thin Films Materials, edited by H. S. Nalwa (Academic, New York, 2002), Chap. 2, Vol. 5, p. 61.

${ }^{4}$ B. Balamurugan, I. Aruna, B. R. Mehta, and S. M. Shivaprasad, Phys. Rev. B 69, 165419 (2004).

${ }^{5}$ K. K. Nanda and S. N. Sahu, Appl. Phys. Lett. 79, 2743 (2001).

${ }^{6}$ V. Erokhin, S. Carrara, H. Amenitch, S. Bernstorff, and C. Nicolin, Nanotechnology 9, 158 (1998).

${ }^{7}$ Y. Chan, J. S. Steckel, P. T. Snee, J. M. Caruge, J. M. Hodgkiss, D. G. Nocera, and M. G. Bawendi, Appl. Phys. Lett. 86, 073102 (2005).

${ }^{8}$ M. M. Janusik, A. Kassib, J. Boucle, J. F. Bardeau, S. Kodjikian, and A. Desert, J. Phys.: Condens. Matter 17, 5101 (2005).

${ }^{9}$ S. Y. Ren and J. D. Dow, Phys. Rev. B 45, 6492 (1992).

${ }^{10}$ B. Balamurugan, B. R. Mehta, and S. M. Shivaprasad, Appl. Phys. Lett. 79, 3176 (2001)

${ }^{11}$ C. Q. Sun, Phys. Rev. B 69, 045105 (2005).

${ }^{12}$ K. Borgohain, J. B. Singh, M. V. R. Rao, T. Shripathi, and S. Mahamuni, Phys. Rev. B 61, 11093 (2000).

${ }^{13}$ B. Balamurugan, B. R. Mehta, and S. M. Shivaprasad, Appl. Phys. Lett. 82, 115 (2003).

${ }^{14}$ V. L. Colvin, A. P. Alivisatos, and J. G. Tobin, Phys. Rev. Lett. 66, 2786 (1991).

${ }^{15}$ T. Maruyama and T. Morishita, Appl. Phys. Lett. 69, 890 (1996).

${ }^{16}$ M. Asano, K. Umeda, and A. Tasaki, Jpn. J. Appl. Phys., Part 1 29, 1985 (1990).

${ }^{17}$ U. Hahn and W. Weber, Phys. Rev. B 53, 12684 (1996).

${ }^{18}$ C. D. Wagner, W. M. Riggs, L. E. Davis, and J. F. Moulder, in Handbook of X-ray Photoelectron Spectroscopy, edited by G. E. Muilenberg (PerkinElmer, Eden Prairie, MN, 1979), p. 83.

${ }^{19}$ A. Balzarotti, M. D. Crescenzi, R. Messi, N. Motta, F. Patella, and A. Sgarlata, Phys. Rev. B 36, 8285 (1987).

${ }^{20}$ F. Wooten, Optical Properties of Solids (Academic, New York, 1972).

${ }^{21}$ L. K. Pan and C. Q. Sun, J. Appl. Phys. 95, 3819 (2004).

${ }^{22}$ C. Q. Sun, T. P. Chen, B. K. Tay, S. Li, H. Huang, Y. B. Zhang, L. K. Pan, S. P. Lau, and X. W. Sun, J. Phys. D 34, 3470 (2001).

${ }^{23}$ C. Q. Sun, L. K. Pan, T. P. Chen, X. W. Sun, S. Li, and C. M. Li, Appl. Surf. Sci. 252, 2101 (2006).

${ }^{24}$ C. Q. Sun, L. K. Pan, H. L. Bai, Z. Q. Li, P. Wu, and E. Y. Jiang, Acta Mater. 51, 4631 (2003).

${ }^{25}$ C. Q. Sun, L. K. Pan, Y. Q. Fu, B. K. Tay, and S. Li, J. Phys. Chem. B 252, 2101 (2006)

${ }^{26}$ G. K. Wertheim, S. B. Dicenzo, and S. E. Youngquist, Phys. Rev. Lett. 51, 2310 (1983).

${ }^{27}$ L. E. Brus, J. Phys. Chem. 90, 2555 (1986).

${ }^{28}$ C. N. R. Rao, G. U. Kulkarni, P. J. Thomas, and P. P. Edwards, Chem.-Eur. J. 8, 28 (2002).

${ }^{29}$ T. V. Buren, L. N. Dinh, L. L. Chase, W. J. Siekhaus, and L. J. Terminello, Phys. Rev. Lett. 80, 3803 (1998). 